УДК 81.25

\title{
КОРОНАВИРУСНАЯ БЕЗЭКВИВАЛЕНТНАЯ ЛЕКСИКА НЕМЕЦКОЯЗЫЧНОГО ЯЗЫКОВОГО ПОЛЯ: ПРОБЛЕМА ПЕРЕВОДА
}

\author{
Марсенич Зорка Живковна \\ Студент \\ Научный руководитель: Нарбут Елена Владимировна \\ к.ф.н., доцент, декан филологического факультета \\ Северо-Восточный государственный университет
}

\begin{abstract}
Аннотация: в статье представлены результаты предварительного анализа лексических изменений в современном немецком языке, связанных с пандемией COVID-19. Выявляются особенности неологизмов коронавирусной безэквивалентной лексики в аспекте их перевода на русский язык. В исследовании использовались методы сплошной выборки, лексического анализа.
\end{abstract}

Ключевые слова: неологизм, безэквивалентная лексика, перевод, COVID-19, немецкий язык.

\section{NON-EQUIVALENT CORONAVIRUS VOCABULARY \\ OF GERMAN LANGUAGE FIELD: \\ PROBLEM OF TRANSLATION}

\section{Marsenich Zorka Zhivkovna Scientific advisor: Narbut Elena Vladimirovna}

\begin{abstract}
The article presents the results of a preliminary analysis of lexical changes associated with the COVID-19 pandemic in the modern German language. It reveals the peculiarities of the neologisms of the coronavirus non-equivalent vocabulary in the aspect of their translation into Russian. The study uses the methods of continuous sampling and lexical analysis.

Key words: neologism, non-equivalent vocabulary, translation, COVID-19, german language.
\end{abstract}


Как известно, в периоды высокой активности общественно-политической и культурной жизни страны процесс появления неологизмов как результат словотворчества, семантической деривации или заимствования тоже становится более интенсивным. Это связано с тем, что в языке как зеркале той или иной культуры отражаются общественное самосознание народа, его менталитет, национальный характер, образ жизни, традиции, обычаи, мораль, система ценностей, мироощущение, видение мира [11, с. 24]. Примером такой языковой активности в наше время может являться пандемия COVID-19.

Пандемия затронула практически все население планеты, а продолжительность данного явления безусловно привела к образованию пласта лексики, являющейся дискурсивным маркером обозначенного процесса.

В этой связи стоит обратить внимание на один своеобразный момент в процессе заимствования. Влияние английского языка на остальные языки остаётся неизменно высоким уже многие годы. Но примечательно то, что возникающие английские слова, связанные с коронавирусной тематикой, с одной стороны, в самом английском языке ощущаются как неологизмы, а с другой стороны, уже становятся неологизмами-заимствованиями в других языках. Например, английский неологизм covidiot, который сегодня является неологизмом и в русском (ковидиот), и в немецком языках (варианты Covidiot и Covididiot). При этом не все английские «коронавирусные» неологизмы прижились в русском языке, как, например, слово homeoffice. В немецком же языке оно приобрело множество производных, таких как Homeofficeeinsamkeit, Homeofficepflicht, Homeofficer, Homeofficegesetz и других.

Но заимствования из английского языка, конечно, не являются основной частью коронавирусного лексического пласта ни русского, ни тем более немецкого языка, в которых развитые механизмы словообразования способны генерировать необходимое количество новых слов, как было продемонстрировано выше. Исследователи и в России, и в Германии делают успешные попытки отобразить формирующуюся языковую коронавирусную картину. Так, «Словарь русского языка коронавирусной эпохи» [9], составленный лексикографами отдела современной русской лексикографии Института лингвистический исследований РАН, попытался отобразить всё то многообразие лексики, возникшей в соответствующий период. Соответственно для немецкоязычного поля Институт немецкого языка им. Лейбница (LeibnizInstitut für deutsche Sprache) и Берлино-Бранденбурская академия наук (BerlinBrandenburgische Akademie der Wissenschaften) в рамках своих электронных 
словарей das Online-Wortschatz Informationssystem Deutsch [13] и Digitales Wörterbuch der deutschen Sprache [12] создали списки коронавирусных немецких неологизмов и пополняют их достаточно часто. Наше исследование в определённой мере базируется на списках неологизмов из данных словарей.

Так как весь мир только переживает пандемию COVID-19 и сроки её окончания пока ещё точно неизвестны, то можно сказать, что мы все находимся внутри процесса формирования информационного поля. Поэтому сложно отследить то количество коронавирусного контента, возникающего в медиапространстве ежедневно. Сложно также определить, какое количество такого контента ещё только будет создано в будущем. Однако не вызывает сомнений то, что создаваемые тексты будут требовать перевода с одного языка на другой. Данный материал, естественно, будет характерно окрашен. И если для переводчика, заставшего ход пандемии, это, скорее всего, не вызовет особых трудностей в его работе, то для людей, не заставших пандемию и вследствие этого слабо погруженных в дискурс, коронавирусная лексика может стать серьёзной переводческой проблемой. Этим, на наш взгляд, определяется актуальность работы.

Также мы не можем с точностью сказать, какие конкретно слова из ряда сегодняшних неологизмов прочно закрепятся в языке и перестанут ощущаться как слова новые, необычные, ведь процесс их формирования ещё не завершён. На основе анализа тематических словарных списков $[12,13]$ и метода выборки мы можем сделать предположение о той лексике, которая может представлять сложность при переводе произведений на «вирусную» тематику. Большую часть такой лексики составляет лексика по той или иной причине безэквивалентная.

Безэквивалентная лексика является одной из категорий, которая вызывает значительную трудность в процессе перевода. Проблемами безэквивалентной лексики занимались многие известные лингвисты, такие как Я. И. Рецкер, А. О. Иванов, А. Д. Швейцер, В. Н. Комиссаров. Они по-разному определяли это явление; мы же остановимся на определении Л. С. Бархударова, дефинирующего данный тип лексики как «лексические единицы (слова и устойчивые словосочетания) одного из языков, которые не имеют ни полных, ни частичных эквивалентов среди лексических единиц другого языка» [1, с. 57]. Однако важно понимать, что «безэквивалентность» вовсе не равно «непереводимость». Непереводимыми остаются только аналогичные значения, 
а не сами лексические единицы [3]. Таким образом, выделяются различные уровни безэквивалентности $[1,3,7]$ :

1. Безэквивалентность по причине отсутствия соответствующих реалий (вещественная безэквивалентность).

2. Безэквивалентность по причине отсутствия тождественной лексической единицы (лексико-семантическая безэквивалентность).

3. Безэквивалентность по причине различия лексико-семантических характеристик (стилистическая безэквивалентность).

В контексте нашей работы будут рассматриваться первые две группы лексики, так как лексическо-семантические значения коронавирусного языкового поля русского и немецкого языков во многом схожи, и разница в их восприятии либо ещё не сформировалась, либо не сформируется вовсе.

Для удобства, а также наглядности, выделенная нами лексика представлена в виде таблицы. Слова в таблице размещены по времени их появления в языковом поле (некоторых слов - конкретно в контексте пандемии коронавируса) в соответствии с данными немецкоязычных словарей $[12,13]$.

Таблица 1

\begin{tabular}{|c|c|c|}
\hline $\begin{array}{c}\text { Уровни } \\
\text { безэквивалентности }\end{array}$ & Примеры & $\begin{array}{c}\text { Вариант описательного } \\
\text { перевода }\end{array}$ \\
\hline \multirow{5}{*}{$\begin{array}{c}\text { Вещественная } \\
\text { безэквивалентность }\end{array}$} & die „Notbremse“ (07.04.2020) & $\begin{array}{l}\text { Меры по предотвращению } \\
\text { распространения коронавируса в } \\
\text { зависимости от количества } \\
\text { заболевших }\end{array}$ \\
\hline & die Corona-App (08.04.2020) & $\begin{array}{l}\text { Программа для смартфонов, } \\
\text { позволяющая отследить } \\
\text { количество заражений } \\
\text { коронавирусом }\end{array}$ \\
\hline & der Coronaradweg (02.05.2020) & $\begin{array}{l}\text { Специальные дорожки для } \\
\text { велосипедистов, позволяющие } \\
\text { соблюдать социальную } \\
\text { дистанцию при перемещении } \\
\end{array}$ \\
\hline & der Bürgertest (12.03.2021) & Бесплатный тест на коронавирус \\
\hline & 1G-/2G-/3G-Regel (23.06.2021) & $\begin{array}{l}\text { Правило, которое позволяет } \\
\text { определённые действия только } \\
\text { привитым, переболевшим или } \\
\text { протестированным }\end{array}$ \\
\hline \multirow{3}{*}{$\begin{array}{c}\text { Лексико-семантическая } \\
\text { безэквивалентность }\end{array}$} & die Ansteckungsgefahr (16.03.2020) & Страх заразиться коронавирусом \\
\hline & die Spuckwand (08.04.2020) & $\begin{array}{l}\text { Защитная прозрачная } \\
\text { перегородка, используемая в } \\
\text { различных учреждениях, а также } \\
\text { в транспорте }\end{array}$ \\
\hline & coronafrei (18.04.2020) & $\begin{array}{l}\text { 1. Отменённый по причине } \\
\text { коронавируса } \\
\text { 2. Места без случаев заражения } \\
\text { коронавирусом } \\
\text { 3. Чувствующий себя } \\
\text { свободным от ограничений }\end{array}$ \\
\hline
\end{tabular}


Продолжение Таблицы 1

\begin{tabular}{|l|l|}
\hline coronabedingt (06.05.2020) & $\begin{array}{l}\text { Что-либо, произошедшее во } \\
\text { время пандемии (из-за пандемии) }\end{array}$ \\
\hline die Abstandsregel (26.05.2020) & $\begin{array}{l}\text { Правило, регулирующее } \\
\text { социальную дистанцию }\end{array}$ \\
\hline die Kontaktbeschränkung (18.06.2020) & Ограничение контактов \\
\hline $\begin{array}{l}\text { der Geruchs-/Geschmaksverlust } \\
\text { (07.07.2020) }\end{array}$ & Потеря обоняния и вкуса \\
\hline die Maskne (06.08.2020) & $\begin{array}{l}\text { Высыпания на лице, вызванные } \\
\text { ношением маски }\end{array}$ \\
\hline das Risikogebiet (08.10.2020) & $\begin{array}{l}\text { Зона сильного распространения } \\
\text { коронавируса }\end{array}$ \\
\hline verimpfen (09.10.2020) & $\begin{array}{l}\text { Вводить одну дозу вакцины } \\
\text { нескольким людям }\end{array}$ \\
\hline pandemiemüde / coronamüde (26.10.2020) & $\begin{array}{l}\text { Уставший от пандемии } \\
\text { коронавируса }\end{array}$ \\
\hline der Querdenker (29.11.2020) & $\begin{array}{l}\text { Человек, считающий пандемию } \\
\text { вымыслом }\end{array}$ \\
\hline der Homeofficepflicht (18.01.2021) & $\begin{array}{l}\text { Обязанность работать удалённо } \\
\text { (из дома) }\end{array}$ \\
\hline das Ausgangsverbot (02.03.2021) & Запрет на выход из дома \\
\hline mütend (24.03.2021) & $\begin{array}{l}\text { Уставший и находящийся в } \\
\text { ярости человек }\end{array}$ \\
\hline der, die Impfunwillige (05.05.2021) & Люди, нежелающие прививаться \\
\hline der Impfbooster (03.07.2021) & Препарат для ревакцинации \\
\hline
\end{tabular}

Даже небольшая выборка из широкого пласта неологизмов показывает, что данная лексика в основном образована способом словосложения, являющимся традиционным и наиболее распространённым способом образования существительных в немецком языке. Большинство композитов с основой Corona- решено было не указывать, так как их анализ и стратегии перевода ранее рассмотрены в работе Е. М. Игнатовой и Е. В. Пивоваровой [4].

Стратегии перевода безэквивалентной лексики зависят от прагматических целей исходного текста и перевода [7, с. 175]. Дальнейшая наша работа предполагает расширение данного списка лексики и поиск наиболее релевантных переводческих решений.

\section{Список литературы}

1. Бархударов Л. С. Язык и перевод. - М.: «Международные отношения», 1975. $-240 \mathrm{c}$.

2. Земская Е. А. Словообразование как деятельность. - М.: Наука, 1992. $-220 \mathrm{c}$.

3. Иванов А. О. Безэквивалентная лексика. - СПб.: Типография издательства СПбГУ, 2006. - 192 с. 
4. Игнатова Е. М., Пивоварова Е. В. Орфографические особенности, семантические связи и способы перевода композитообразований концептосферы "Corona" (на материале немецкого языка) // Филологические науки. Вопросы теории и практики. Том 14. Выпуск 4. - Тамбов: Изд-во «Грамота», 2021. - с. 1148-1154.

5. Москвитин Е. В. Немецкие неологизмы в период пандемии коронавируса SARS-CoV-2 // Филологические науки. Вопросы теории и практики. Том 14. Выпуск 9. - Тамбов: Изд-во «Грамота», 2021. - с. 2792-2796.

6. Найдич Л. Э. Павлова А. В. Трубочист или лорд? Теория и практика немецко-русского и русско-немецкого перевода. - СПб.: Златоуст, 2015. - 408 с.

7. Павлова А. В., Светозарова Н. Д. Трудности и возможности руссконемецкого и немецко-русского перевода. - СПб.: Антология, 2012. -480 с.

8. Розенталь Д. Э., Голуб И. Б, Теленкова М. А. Современный русский язык. - М.: Айрис-пресс, 2003. - 448 с.

9. Словарь русского языка коронавирусной эпохи. - СПб: Институт лингвистических исследований РАН, 2021. - 550 с.

10. Степанов М. Д. Теоретические основы словообразования в немецком языке. - М.: Высшая школа, 1984. - 264 с.

11. Тер-Минасова С. Г. Язык и межкультурная коммуникация, Москва: Издательство «Слово», 2000. - (Учеб. пособие) - М.: Слово/Slovo,2000. - 146 с..

12. DWDS-Themenglossar zur Covid-19 Pandemie [Электронный ресурс]. URL: https://www.dwds.de/themenglossar/Corona (дата обращения 10. 12. 2021)

13. Neuer Wortschatz rund um die Coronapandemie. [Электронный pecypc]. URL: https://www.owid.de/docs/neo/listen/corona.jsp (дата обращения 10. 12. 2021)

(C) 3. Ж. Марсенич, Е. В. Нарбут, 2021 